Childbed and Maternity Hospitals, ${ }^{5}$ Dr. Matthews Duncan says: "In a well-managed hospital they die at the rate of 1 in 100 ; all the country over the mortality is probably not much less, in the best private practice it appears to be greater." "In the years of my private practice of which I have preserved records $I$ find 8 deaths in 736 cases, or 1 in 92." This was written in 1870 , before antiseptic midwifery came in practice.

Why the sublimate treatment should not be adopted in private practice as well as in hospitals I am at a loss to understand. In my lecture to the midwives that I have spoken of, giren in 1887, I gave them a list of what I order to be ready in the bouse of every patient who expects me to attend her in her confinement, and amongst the things was what would make half a gallon of sublimate solution ( 1 in 1000), labelled "To be used with an equal part of hot water as a lotion"; and I have continued this, very much to my satisfaction, ever since, and $I$ have used the irrigation just as in the hospital practice and have never seen a sign of mercurial poisoning. In July, 1881, I had the great vnisfortune to lose my first private patient, and from puerperal septicæmia. This was before the days of sublimate and sterilising instruments, but not before the introduction of other antiseptics, and every precaution had been taken by the use of carbolic lotion and carbolised cream. It was a forceps delivery after forty hours labour in a primipara; an occipito posterior presentation; and the perineum was partially ruptured She became feverish after a rigor on the fourth day and died on the thirteenth day after delivery. The most unremitting attention failed to save her life. I cannot tell you the distress the loss of this patient-a young wife-caused me. Only those of you who have had similar losses can realise what it was. I told you in my address last January of a case of puerperal peritonitis in a patient delivered in December, 1890, who was attended by me under the most strict sublimate lines. It was a genuine case of acute septic peritonitis occurring a few hours after delivery, and although no necropsy was made. I feel convinced, from the reasons I gave you, that it was caused by ruptare of a pyosalpinx, as in those cases narrated by Dr. Michie of Nottingham in his paper read before this society in May, $1885^{6}$ If this case be excepted, no case of septicemia has occarred in my private practice since I commrenced the use of corrosive sublimate. It gives me a feeling of protection I cannot over-estimate. I feel : are if its employment in midwifery were generally adopted by practitioners for their hands and for varinal irrigation the Registrar-General's reports of the mortality from puerperal septicæmia would very soon show a difference, and in these days of portable compressed drugs there is no reason why it should not be almost universally used, even among the very poor. To my mind it would be a great pity if Dr. Bantock's recent reference to mercurial poisoning were to deter practitioners from employing it. It is only right, however, that it should be pointed out to them what may result if it be improperly used.

In the annual report of the General Lying-in Hospital for 1883 the medical report, signed by Dr. (now Sir John) Williams and Dr. Champneys, says that 342 women were confined, of whom 3 died (1 in 114), 2 from septicæmia, quite independent of one another, "a percentage which testifies to the healthy condition of the hospital." This was during the time that antiseptics were employed there, bat, you will note, before the corrosive sublimate was commenced, and the committee add in presenting this medical report to the governors: "The committee beg to tender their congratulations to the eminent surgeon to the hospital, Sir Juseph Lister, Bart., to whom this and other institutions are so much indebted for the satisfactory medical results obtained through the system with which his name is associated."

Sir William Priestley con luded his paper rear before the *) Jstetrical Socievy of London in July, 1885, entitiled "Notes of a Visit to some of the Lying in Hospttals in the North of Europe; and particularly on the Advantages of the Antiseptic System in Obstetric Practice," with these words: "Ample cunds and sufficient space are necessarily most potent aids in waging warfare with disease in ho:pitals, but, even with Jimited moans and space, absolute cleanliness, supplemented Gy the antiseptic system, may in our own country have a large influence for good, and the labours of our illustrious Lister prove of equal value to the obstetrician as to the surgeon.

5 Edinburgh : A. \& C. Black, 1870 p. 116

Pregancy Complicated by Suppuration in the Pelcis,-British Cifráccuogical Journal, 1895, p. 160 .
If I am not mistaken some of our Fellows," says Sir William Priestley, "can tell us of triumphs of this kind in the lying. in hospitals of London." I hope you will think that 1 have this evening succeeded in doing so.

I feel that I cannot conclude my address better than by saying that though numerous peerages have been conferred upon those " waging warfare " resulting in the destruction of life and victory (!) never has one been more worthily bestowed than on "our illustsious Lister" for the victory gained by him in "waging warfare with disease in hospitals," resulting in such an enormous saving of life among our fellow creatures.

I cannot sit down without congratulating the society upon its selection of $m y$ successor in this chair. Professor Mayo Robson will fill it, I am sure, with dignity, eloquence, and good judgement, that have never, at all events, been surpassed by any of his predecessors.

In bidding you farewell, I thank you all for the kindness you have displayed towards me and the assistance you have given me during the two years that I bave presided over you, a period in my life of which I shall always have the happiest recollections.

\section{SYPHILITIC DISEASE OF THE} HEART WALL.

BY SIDNEY PHILLIPS, M.D., F.R.C.P.LOND,

PHYSICLAN AND JOINT LECTURER ON MEDICINE AT ST. MARY'S HOSPITAL: SENIOR PHYSICLAN TO THE LONDON FHVER HOSPITAL; PAYSICIAN TO THE LONDON LOCK HOSPITAT.

A PROFESSIONAL man, aged fifty-three years, who in his youth contracted syphilis had from time to time been troubled with sores on the tongue, and in 1890 suffered from epileptiform convulsions, of which a grave prognosis was given by the physician whom he consulted, but which gradually ceased to occur. A child of his had been under treatment by a well-known surgeon for psoriasis suspected to be of syphilitic origin. At Easter, 1894, while on a few days' holiday in the country, he went to bed apparently quite well, but was suddenly taken ill in the night. The physician who was called to see him has kindly given me the following account of his symptoms: "He was walking about the room in an agony of pain which he described as unendurable. The lower part of the sternum and epigastrium were the chief seats of pain, which went through to the back and also extended down the left arm ; there was no marked pallor, no cyanosis, no laboured breathing; the pulse was 60 and laboured ; there were no signs of valvular mischief about the heart and no irregularity of rhytbm; there was a sense of distension of the abdomen. I ascertained this was the first attack of severe pain he had had, but there had been previously some discomfort and some pain running down the arm, and that his heart had been suspected of being at fault." Recovering under the free administration of morphia he returned to town and to work against medical advice; but eighteen days after this attack of pain, on returning home from business, he quietly expired in an arm-chair while reading the evening paper.

I made the necropsy with the medical man who had attended him from time to time in London. There were no signs of disease anywhere, except that there were about two drachms of clear fluid in the pericardial sac and some soft bands of fresh lymph about balf an inch long, easily broken across, extending from the anterior wall of the left ventricle just above the apex to the adjacent surface of the pericardium; on the surface of the ventricle beneath the ly $\mathrm{mph}$ was a small area of ecchymosis the size of a shilling. The heart wall in this situation felt harder than elsewhere and on section this thickening was seen to be produced by a yellow homogenenus-looking substance much resembling in appearance the almond of a wedding-cake. It was situate between the endocardium within and the pericardium without, entirely replacing the muscular fibre, and formed a nodule with a diameter of that of a florin in the anterior wall of the ventricle, which it thickened and toughened. The rest of the heart and the cardiac valves were healthy, except that the left ventricle was somewhat dilated. Mr. J. J. Clarke, pathologist to St. Mary's Hospital, 
$22 \ddagger$ The LANCET,] DR. SIDNEY PHILLIPS: SYPHILITIC DIEEASE OF THE HEART WALL. [JAx. 23, 1897.

Table of Fatal Cases of Sxphilimil Disease of me Heart Will.

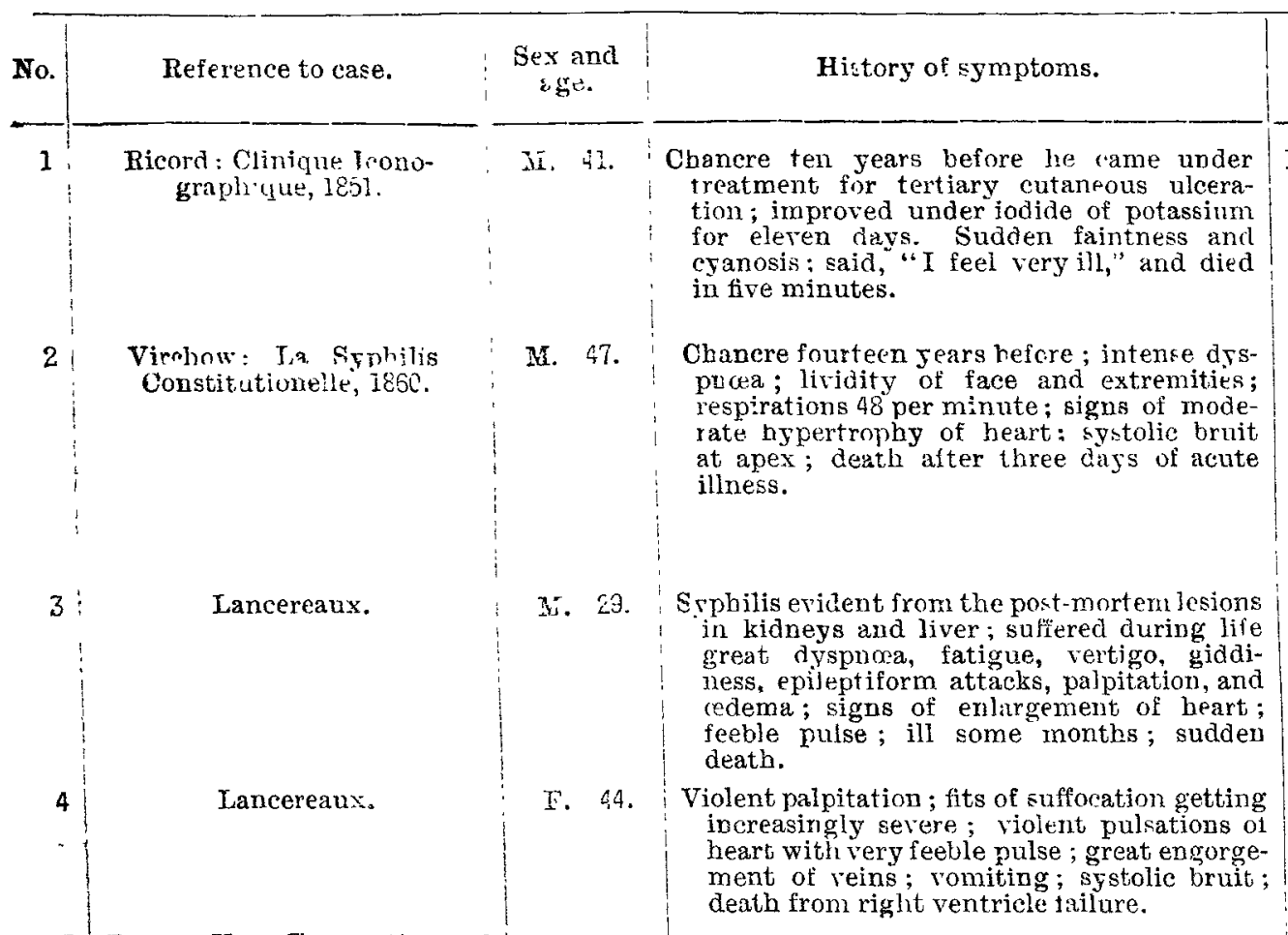

5 Burney Yeo: Transactions of the Pathological Socity,

W. Oayles: Transactions of the Pathological society, 1875.

7 A. P. Gould: Transactions of the Patholoy:cal society, 1877 .

8 T. Barlow: Transartions of the Patuological Society, 1877

9 Mannino: Jomale Italiano, 1882.

10 Ifentercon: Transaetions of the Patholngical suciet $y$, loc2.

Goouthart: Transactions of th Pathologicui Societ $y, 1857$.

3. 28. History of syphilitic infection some years previously; found dead in bed : he had gone to hed in bis usual health after taking from 20 to 30 grains of chloral, which he had been in the habit of doing.

M. 40. Date of infection nnknown; for some time dyspncea and cardiac pain; fell dead in a public-house after walking across some fields when in apparently good bealth.

M. 42. Three years after infection anginal attacks lasting till death two years linter; for one vear before dearh orthopncea, cough, swelled feet, systolic and diastolic bruits, signs of right heart engorgement.

M. 26. Seven years after infection illness with dyspnota, cough, albuminuria; systolic byspnota, cough, albuminuria; systolic tricle; diagnosis of syphilitic heart disease from peculiar feeble contraction of beart from peculiar feeble contraction of beart and empty arteries; spphilitic skin erup-

1. 30. Was in good bealth ; suddenly staggored and fell, put hand to heart, and diea in a few minutes; no history of angina.

M. 30. Date of infection unknown; had had a sore throat and eruptions and node on tilia: after being apparently will and quit cheerful in the evening died in his armchair the same night, as if he had been sleeping; a prescription for mercury found

12 Goodhart: Transactions of the Pathologiral society, 1087.

13 Turner: Brit. Med. Jour., 1830 , vol. i., p. 657.

14 Pitt: : Transactions of the Pathological Society, 180 :

15 Bolleston: Transactions of the Patholugucal Society. 1893.

16 Sbarkey: Transactions of the Pathological scciety, 1885.

17 McNalty : Medical Times, 1570 in his pocket dated nine montlis previously.

r. 30. Dropped dead in the street; supposed to have been a prostitute.

11. 37. Infection ten years previously; for some years precordial pain, palpitation, gidoiness; increased four days hefore admission to hospital; cardiac duiness extended to right ; rough systolic murmur at base of 40, when he died from syncope four weeks after admission to hospital.

11. 23. Had had slight pain in heart, but not enough to give up work; died suddenly while lifting a weight.

MI. 34.

Death from an accilient.

M. 44. History of syphilis; epigastric pain, cough, short breath, fetble pulse, general dropsy.

Mr.
adilit.
Post-nortem appearances.

Heart hypertrophied; clots in both ventricles lymph on pericardium; patches of infiltrafion in the wall or coth rentricles, especially of the riglit ; some hard, like scirrhus, others softening, with complete destruction of murcle tiore; old eccbymoses in wall of left ventricle.

Left ventricle dilated and a diverticnlum the size of a nutmeg near its apex with thickened endocardium and adherent thrombus : the two papillary muscles quite shrivelled. two lapilary muscles quite shrivelled; general fibroid infiltration replacing the muscle wall in right ventricle, some gum mata, and an aneurysmal dilatation below chiefly affected; pericardial adhesions.

Left rentricle dilated and thickened extensjrely $l y$ an iufiltration chiefly about base. of the heart and mitral orifice; columno infiltration ; evdocardium attacked.

Left ventrirle bealthy; right ventricle dilated and infundibulum the reat of tough infiltration stiffening its wall ; in its substance little nodules (gummata) "like small-pox eruption": rest of ventricle healthy.

Gummata involving the musculi papillares and corda tendinese of left ventricle.

Lefo rentricle hypertrophied, and in its wall several round nodules were projecting into. the cavity of the ventricle as well as exter nally and involving the bases of the musculi papillare:

Left side of beart quite healthy; right rentricle normal thickness, all trace of muscle tibre in it, replaced by a whitish infiltration. it involved the septum and many of the musculi pectinati.

Syphilitic inf'tration of wall of left ventricle arouna aortic orifice and formation here of as eurysm of heart wall; not ruptured.

Infiltration of large fibroid patches, creaking on section, in anterior wall of both ventricles; a hard fibrous corkl in septum. left rentuicle chiefly enlarged.

A mass of fibroid tissue in the septum $2 \times 1$ inches thick and muscular substance vermeated by gummatous nodules; narroxing of lumen of coronary arteries; nodules in pericardium over left veritricle.

Gummatous infitration of the muscle of the left ventricle, which, forming an aneurgsm had ruptured into pericardial sac.

Left ventricle dilated and hypertrophieà'; it and the septum the seat of syphilitic infiltration.

Infundibulum three-quarters of an inch from the pulmonary valves surrounded by, and considerably contracted by, infiltration and projecting into left ventricle; left coronary artery blocked by a thrombus; gumma in testis.

Gummat ous cellular infiltration involring botb ventricles, especiaily the left; aneurysm of posterior wall of left ventricle near apex, which had ruptured; syphilitic testis.

In right ventricle and in septum rentriculorum were many gummatous nodules gummata in testis, and scars on penis and groin.

Heart enormously bypertrophied, but rery thin near apex of left ventr

Heart somewhat atrophied, with numerens gummata in its wall from size of a pin's heai to a pea; pericardial adhesions. 
Table or fatal Cases of Syphilitic Disease of the Heari Wall-continued.

\begin{tabular}{|c|c|c|c|c|}
\hline No. & Reference to case. & $\begin{array}{l}\text { Sex and } \\
\text { age. }\end{array}$ & History of symptoms. & Post-mortem appearances. \\
\hline 18 & $\begin{array}{l}\text { Moxon: Transactions of the } \\
\text { Pathological Society, 1874, } \\
\text { quoted by Fagge, and Guy's } \\
\text { Hospital Reports, 1867. }\end{array}$ & M. ( $)$ & $\begin{array}{l}\text { Sudilenly reeled and fell dead whilst walking } \\
\text { across London-bridge. }\end{array}$ & $\begin{array}{l}\text { Left ventricle, extensive } \\
\text { of tibix; gummata in }\end{array}$ \\
\hline 19 & $\begin{array}{l}\text { Fuller: Transactions of the } \\
\text { Pathological Society, } 1853 \text {. }\end{array}$ & M. 45 . & $\begin{array}{l}\text { Dit suddenly ten minutes after baving a fit } \\
\text { in bed in a workhouse to which he had } \\
\text { been admitted a few hours before; had gone } \\
\text { to bed apparently well. }\end{array}$ & $\begin{array}{l}\text { Extensive fibroid infiltration of wall of left } \\
\text { ventricle completely destroying its muscular } \\
\text { tissue; gummata in right ventricle. }\end{array}$ \\
\hline 20 & $\begin{array}{l}\text { Haldane: Edinburgh Medical } \\
\text { Journal, } 1868 .\end{array}$ & F. 25 & $\begin{array}{l}\text { A. prostitute who, soon after eating a good } \\
\text { slluper and appearing well, died while } \\
\text { walkiog downstairs. }\end{array}$ & $\begin{array}{l}\text { The septum entirely destroyed by syphilitic } \\
\text { infiltration and so also part of the wall of } \\
\text { left ventricle; gummata in right ventricle; } \\
\text { no other signs of syphilis. }\end{array}$ \\
\hline 21 & Phillips: Case sbove reconded. & M. 53. & $\begin{array}{l}\text { Infection many years previously; had had } \\
\text { syphilitic skin eruption and other sym- } \\
\text { jtoms of constitutional syphilis; anginal } \\
\text { attack eighteen days before sudden death } \\
\text { while reading in an arm-chair. }\end{array}$ & $\begin{array}{l}\text { A gumma the size of pigeon's egg in left, ven- } \\
\text { tucle anterior wall close to apex of heart, } \\
\text { destroying muscular fibre and setting up } \\
\text { slight local pericarditis. }\end{array}$ \\
\hline 22 & Luehert. & $\longrightarrow$ & $\begin{array}{l}\text { Date of infection unknown, but syphilitic } \\
\text { skin eruption, negrosis of palate and nodes } \\
\text { ou scalp; a systolic brait. }\end{array}$ & $\begin{array}{l}\text { In right ventricle close to pulmonary valves } \\
\text { two gummata and a third a little way off } \\
\text { endocardium thickened over the gummata. }\end{array}$ \\
\hline 23 & $\begin{array}{l}\text { Kronig: Berliner Klinische } \\
\text { Wochenschrift, November, } \\
\text { 1895. }\end{array}$ & M. 33. & $\begin{array}{l}\text { Oppression eight days; ir egular pulse; in- } \\
\text { ereased cardiac dulness; systolic bruit at } \\
\text { left apex; died whilst getting quietly into } \\
\text { bed. }\end{array}$ & $\begin{array}{l}\text { Gummata in left ventricle; aneurysmal bulg- } \\
\text { ing and rupture of the left ventricle near } \\
\text { septum; the aneurysmal bulging pro- } \\
\text { jected septum into right ventricle. }\end{array}$ \\
\hline 27 & $\begin{array}{c}\text { London Hospital Museun, } \\
\text { No. } 1420 .\end{array}$ & HI. (allult). & $\begin{array}{l}\text { Disrinct history of syphilis. Suddenly } \\
\text { dropped dead while singmg a song; until } \\
\text { that moment was to all appearance in } \\
\text { perfect health. }\end{array}$ & $\begin{array}{l}\text { A soft, lobulated, gummatous growth in } \\
\text { muscuiar wall of left ventricle. }\end{array}$ \\
\hline 25 & $\begin{array}{l}\text { Sir D. Duckworth : Transactions, } \\
\text { of the Clinical Sorlety, 1895. }\end{array}$ & 2I. 33 & $\begin{array}{l}\text { Suddenly fell in the street and expired when } \\
\text { carrying his little boy. }\end{array}$ & $\begin{array}{l}\text { Evidences of previous syphilis on tongue and } \\
\text { glans penis. Gumma in left lung; recent } \\
\text { gummatous growth at base of left ventricle, } \\
\text { and an older gumma near heart's apex. }\end{array}$ \\
\hline
\end{tabular}

found the yellow material to present the usual appearances of gummatous tissue; the heart is now in the museum of the hospital.

So long ago as 1842 Ricord ${ }^{1}$ described two cases of syphilitic disease of the heart wall, and in his "Clinique Icono:graphique," Plate XXIX., he gives an admirable coloured illustration of a syphiiitic heart lesion very similar to that I have just recorded. Virchow in $1860^{2}$ described other cases, and 0 ppert ${ }^{3}$ in 1868 was able to collect eight recorded cases of gummata of the heart. Since then from time to time postmortem specimens of the affection have been exhibited at the Pathological Society of London and elsewhere. The table given above shows abstracts of the history, where such was obtainable, and of the lesions found in twenty-fire cases. In all these cases the pathological changes consisted in a deposit in the muscle of the heart of a substance which in the early stage was soft and yellow in colour and occurred either as nodules, varying in size from that of a pin's head to that of a large marble, or as a more or less widespread infiltration; the substance destroyed and replaced the cardiac muscle so that eventually not a trace of muscular sibre could be detected; it sometimes projected the endocardium lying over it within the heart or the visceral layer of pericardium on the outside of the heart. The infiltration in many cases resulted in a great thickening of the heart wall. producing a false hypertrophy ; in other cases it so weakened the heart wall that it yielded to the intra-cardiac pressure and dilatation resulted, the heart wall in extreme cases being greatly attenuated; occasionally there was produced a local extrusion of the thinned cardiac wall, giving a cardiac aneurysm. In some of the cases of cardiac syphilis the infiltration became white in appearance and tough in texture, creaking on section, and where widely deposited if caused the heart wall to become stiff and to gape on section. In one recorded case a gummatous nodule softened and dissharged itsel in in the hear's cavity, but such an occurrence is quite erceptional. The deposit, whether nodular or diffuse, occurred in the septum of the heart or in one or both of the rentricles. The cases recorded are not numerous enough to base an estimate upon of any value as to the relative irequency of the affection on the two sides of the heart. Any part of the ventricle wall may be affected; the base, it would appear, rather the most often. In some cases the deposit was close to the heart's apex, as in the case at the head of this paper. The infiltration frequently extended

1 Gazette des Hôpitaux, 1845, No. 101 Ia Syphilis Constitutionelle, p. 108. 3 fisoeral Syphilis, 1868 into the columnæ carncæ, softening them or causing their rigidity or contraction, and in one case leading to union of adjacent musculi papillares. The pericardium was occasionally the seat of gummatous nodules, and local pericarditis arose occasionally over these nodules.

The microscopic changes in all these cases were similar to those found in syphilitic fibroid and gummatous changes in other parts of the body. It will have been seen, too, that syphilis produces the same gross changes in the heart as it does in other internal viscera, for example, the testis-viz., a general fibroid infiltration or gummata or both together. In the heart the essential change which syphilis produces is a replacement of the muscular tissue by a round-celled fibroid tissue which, whether it occur as nodules only or as a more widespread change, leads to dilatation or hypertrophy or merely rigidity of the heart wall, and has this uniform result, that it impairs or interferes with the heart's contraction. Now diffuse ilbroid change in the heart wall occurs no doubt from other causes than from syphilis, and, as was pointed out by Fagge, ${ }^{4}$ it is not possible to tell by examination after death whether the changes are or are not of syphilitic origin, except in those cases where there are actually gummata. But in the cases I have included in the table as the basis of this paper there was in every one a distinct history of syphilitic infection, or there were syphilitic changes in other organs than the heart, or there were actual gummata in the heart wall. These cases, therefore, may be taken as undoubted examples of syphilitic heart disease.

\section{SYMPTOMATOLOGY.}

Most of the cases have been recorded to illustrate the pathological conditions produced in fatal cases and comparatively little attention has been directed to the nature of the symptoms produced by syphilitic disease of the heart wall during life; but Ricord, Lancereaux, Mannino, Buchwald, Semmola, and others have written upon the clinical aspects. Lancereaux writes: "Syphilis of the heart is recognisable by a grouping of symptoms, which are palpitation, dyspncea, and then, as little by little the beart dilates, a systolic bruit develops and later anasarca." Buchwald ${ }^{5}$ describes the symptrms as " headache, dizziness, flashes of light, loss of strength, palpitation, dyspnœea, feverishness, sore-throat, and in some cases symptoms of angina pectoris and neuralgic pains like aneurysm; the cases in which the heart insufficiency can no longer be influenced farourably quickly run downbill, developing marked anæmia

Transactions of the Patbological Soriety, vol xxi.

5 Deutsche Medicinische Wochenschrift, Dec. 26th, 1889 . 
and consecutive kidney disease and sometimes pulmonary hæmoptysis. The majority of cases show a great and rapid improvement under anti-syphilitic treatment." Semmola ${ }^{\circ}$ writes: "Syphilis is one of the most troublesome and ill-defined pathogenic diseases of the heart, commencing not with direct functional disturbance, but with vague nervous diffuse phenomena without certain features of recognition; neitber percussion nor auscultation will assist the investigator in the incipient stages of the disease; the morbid process is slow in progress, exhibiting manifestations of a change in the ventricular structure without evidence of dilatation or hypertrophy; the absence of the latter makes the clinical picture of the morbid changes difficult to reconcile with the more commonly met with cardiac diseases." These descriptiuns, though agreeing to some extent with one another, make no distinction between the widely varying conditions producible by syphilitic disease of the heart. 'There may be only a gumma, or a widespread general infiltration, or extensive dilataticn or hypertrophy, or a cardiac aneurysm on either or both sides of the heart, and it is obvious, therefore, that no one description of symptoms can be given which will be applicable to all cases.

In this paper I propose to inquire whether the symptoms of syphilitic disease of the heart wall are sufficiently distinctive to enable us to make an approach to a correct diagnosis of the condition during the lifetime of the patient.

S'mptoms produced by gummata of the left ventricle.-In Case 15 in the table, in which death occurred from the effects of an accident, and in Case 17, where it resulted from an arric aneurysm, numerous small gummata were found post mortem in the heart wall, and in the Museum of the Royal C llege of Surgeons of England is a very beautiful specimen (No. 2959) of a heart with gummata the size of a pea in its wall; the patient from whom it was taken had been under observation for a considerable period for symptoms of verebral syphilis, from which he died. In none of these cases had there been any symptoms of heart disease during life, and in none of thern did death occur from the heart affection. It is evident, therefore, that very small gummata may exist in the heart wall without giving any recognisable evidence of their presence. S) long, however, as they remain so small in size or so situated as to produce no symptoms they do not appear to be dangerous to life or of immediate importance. But the importance of gammata of larger size in the left ventricle is very great, for they may cruse sudden death in the prime of life in otherwise healthy persons, as shown by the case at the head of this paper; hy Case 24, where a man dropped dead after singing a song. having been to all appearances in perfect health until that moment; and by Case 25, of a man aged forty-five years, whn, when walking in the street carrying his little boy, suddenly fell down and expired.

In all these cases there was a gumma in the left ventricle, and it is noteworthy that necropsies show that it is only when the gumma is in the left ventricle that it is liable to produce such sudden death and also only when it is situated near the apex of the ventricle; this, indeed, is what might be expected from what is known of the action of the muscular fibres of the ventricles during systole. Now, although persons may thus die suddenly from cardiac gummata in the midst of apparent health, it must not be concluded they had previously suffered from no symptoms or signs of heart disease. In $x$ uch cases it is often impossible to obtain the patient's previous history or to ascertain if he had suffered from any symptoms, and most of the recorded cases were exhibited as pathol gical specimens with little reference to the previous condition of the patient. It is, therefore, not justifiable to infer that these patients had suffered from no symptoms indicating heart disease because no evidence of such is forthcoming. The case at the head of this paper, for instance, might have been regarded as one of sudden death without any previous cardiac symptoms had it not been that information was subsequently obtained that the patient had a few days before, when away from home, been seized with sudden intense pain, regarded at the time as of gastric origin, but which the after evidence leaves no doubt was a very acute attack of angina pectoris. And in all the cases recorded of sudden death from a cardiac gumma in which the previous condition of the patient has been ascertainable there have been symptoms, slight it may ha. ofren inrermirtine, uften wrongly interpreted, but which might, if our knowledge of the subject was more accurate, have given rise at any rate to a strong suspicion of cardiac yphilis. It is, therefore, of importance to inquire further what are the exact indications which a cardiac gumma may produce.

The fatal cases of cardiac gummata in the table do not lend much assistance, the patients having died under circum stances which prevented the previous history being accurately ascertained. But in Case 21 the patient had beer under careful observation for a long time and there had been nothing more than an attack of angina pectoris, palpi tation, and occasional discomfort about the heart, with such slight physical signs of abnormality that it was thought heart disease might be excluded. From this case and from. the evidence of other recorded cases in which the symptoms cleared up under anti-syphilitic treatment, and in which it was presumable that gummata existed, the symptoms producible appear to be one or more of the following: palpita tion; subjective sensations about the precordium; attacks of angina pectoris; giddiness, faintness, or actual syneopar attacks; epileptiform seizures; and alterations in the force and frequency of the pulse, especially its great rapidity, and in some cases irregularity of the heart's action. The symptoms may be variously associated ; there may be only angina, or palpitation and angina, or tachycardia, or palpitation and syncopal attacks, or they may be grouped in other ways. With these symptoms there are no evidences that the heart is enlarged, but there are usually some physical signs of cardiac action being embarrassed-the heart's impulse may be feeble and the first sound weakened, but more of ten the action is irregular and excited and the impulse abrupt, with a loud first sound; and it is quire possible that a gumma, which is virtually a foreign body in the heart substance, may impede the free action of the muscular fibres immediat $t^{l}$ around it and give rise to over-action of the healthy fibres of other parts of the ventricle.

None of the symptoms which have been enumerated are pathognomonic of cardiac gummata, but there are two of them-viz., angina pectoris and tachycardia-which merit special attention in this connexion.

Argina pectoris.-Angina pectoris is usually associated with physical signs or sy mptoms of heart or valvular disease that can leave no doubt that the angina is dependent on the heart condition; but, as many of the cases in the table show, a gumma of the heart wall may produce angina pectoris with scarcely any other symptoms or signs of heart. discase. Thus, in Case 8 what was subsequently rerified as true angina pectoris was for a whole year the sole symptoms of an eventually fatal syphilitic beart lesion, and in Case 21, except for some occasional palpitation, an attack of severe: angina pectoris was the sole symptom of a cardiac gumma which killed the patient eight een days later. When anginas pain occurs then, even though there be no confirmatory signs of heart disease, we should remember that it may be the indication of a gumma in the heart.

There are some other conditions which will produce anginas pain with a similar minimum of confirmatory symptoms of heart disease-viz., fatty degeneration of the heart and, as. Sir William Broadbent has pointed out, aneurysm at the very root of the aorta within the pericardial sac; also aneurysn of the cardiac wall, of which an example will be given later. The cases in which angina is due to fatly disease can be distinguished from those in which it is due to a gumma, by the fact that fatty disease occurs for the most part after five years of age and syphilitic heart lesions for the most part much earlier in life. Fatty heart is also usually associated with other clinical evidences of it presence, and in syphilitic gummata there will be evidences, or bistory, of previous infection. The other condition from which cardiac gumma may have to be distinguished is aneurysm at the root of the aorta. Sir William Broadbent ${ }^{7}$ points out that "it is not always possible to distinguish between anginoid pain due to aneurysm in this situation and true angina; in the cases of aneurysm the sense of impending death is not so marked a feature of the attacks, and the pain often radiates down the arms instead of alorg the left only, occasionally it shoots down the right arm only. In angina there may be no physical signs of disease of the great vessels; in aneurysm there will be the the ringing second sound and very frequently a diastolic murmur."

Angina pectoris, then, must not be discarded as a symptom 
of heart disease because it is unaccompanied by any other evidences of heart disease; and where fatty degeneration of the heart and aneurysm of the root of the aorta can be excluded it affords a presumption of gumma or aneurysm of the heart, and when on investigation any syphilitic antecedents are discovered in the patient the presumption becomes a strong probability.

I need not enter into the differential diagnosis between gumma and aneurysm of the heart wall, as they are, in fact, stages of the same affection.

Tachycardia, according to Semmola, ${ }^{8}$ is another symptom which sometimes denotes a cardiac gumma, and "it may be," he writes, " the earliest sign of syphilitic disease of the heart wall." He also adds : "The rapid action is constant and not paroxysmal as a mere neurosis ; this is important to recognise, because it is at this period that anti-syphilitic treatment is of most avail." A case recorded by the late Dr. Bristowe ${ }^{9}$ appears to support the observation. A man, aged thirty-eight years, after contracting syphilis, began to suffer from tachycardia, with epigastric pain, but without physical signs of heart disease. $\mathrm{He}$ was little relieved by digitalis or iron, and later developed dyspnoea, anasarca, and dilatation of the heart and died in about a year. No necropsy was made, and the connexion between syphilis and the symptoms does not appear to have been entertained, but the course of the case so exactly resembles that of many of the cases in the table of verified syphilitic heart disease that it appears highly probable that Dr. Bristowe's case was one of syphilitic myocardial change of which the tachycardia was one of the earliest symptoms. I have no case in which tachycardia was verified by post-mortem examination to have been due to gumma; but in a case which $I$ shall. describe later, and in which the post mortem examination showed general fibroid change in the heart wall, tachycardia was one of the earliest symptoms and probably, therefore was produced when the fibroid change was quite localised. This case, however, does not bear out Semmola's dictum that in such cases the tachycardia is constant and not paroxysmal.

It is evident that where tachycardia is an early symptom of fibroid heart change it must be very difficult, or even impossible to distinguish such a case from a mere functional tachycardia, but it is higbly probable that many cases of so-called functional tachycardia are really due to some organic lesion, such as a gumma in the heart, and so also are some of those cases described in young soldiers as " irritable heart."

Gummata of the right ventricle.-The post-mortem exami. nations of the cases in the table show that gummata may occur in the right ventricle as well as in the left. So far as I can ascertain there is no recorded case of death, either sudden or gradual, from a gumma in the right ventricle ; it is, therefore, not possible to say, from postmortem evidence, what symptoms a gumma in the right ventricle may produce. Though not so immediately dangerous to life as gummata of the left ventricle, they are, however, by no means unimportant, for they may interfere with effective action of the right heart, and they tend in time to become aneurysmal and to rupture, or they may become associated with more widespread fibroid disease.

In all the cases in which extensive fibroid disease has been found in the right ventricle dyspnoed has been one of the earliest and most constant symptoms; it is, therefore, probably producible when there is only a gumma or fibroid change of limited extent on the right side of the heart. When dyspnœa occurs without lung disease or left-sided heart disease or other obvious cause, such as anæmia, it is well, therefore, to remember its possible dependence on some fibroid change in the wall of the right ventricle, and this becomes all the more probable if on enquiry we find a history, or signs of, previous syphilis. Angina pectoris, too, may no doubt result from such disease in the right, as it may in the left, ventricle.

The following appear to have been instances of cardiac gummata :-

CASE A. Severe angina without physical signs of cardiac disease; recovery after anti-syphilitic treatment.-A married man, aged thirty years, came to the out-patient department at St. Mary's Hospital on Aug. 12th, 1887. He had contracted a chancre, followed by a syphilitic eruption, twelve years before. Except for an attack of typhoid fever in 1884 his health

Bulletin de l'Académie de Méderine, vol, xxviii, p. 126. 9 Brain, October, 1887. had been good, but in 1877 , or two years after his primary infection, he began to suffer from pains in the cardiac region; he got better, but for the four years previously to 1887 , when I first saw him, he had been subject to attacks of angina which were very severe and in March, 1887, became still more intense. When I first saw him he was very tremulous, having had an attack the same morning; his pulse was 100 per minute, regular, and of good force. He described the attacks as "horrible sensations" felt in the cardiac region and along the course of the left ulnar nerve; during the attack he was afraid to draw breath. The attacks lasted for one or two minutes, but sometimes recarred in a minute or two ; when over there was profuse swealing. He said that when the attacks had passed he was not short of breath and could get about very well, but palpitation came on if he walked fast or ran upstairs. The position of the heart's apex was very difficult to exactly localise; it appeared to be in the fifth space, half an inch below and quite onc inch inside the nipple and was very feeble, while there was a curious throbbing over the right ventricle, and, indeed, over the whole chest; there was no bruit anywhere except at the right apex and at the base of the heart, where the first sound was covered by a thin, hollow, soft bruit, possibly hæmic, being also heard under the left clavicle; the second sound at the right base was short and clicking; the heart's action was very abrupt and forcible, but the pulse was weak, regular, and 100 per minute and the carotids were throbbing. He had been under treatment in America, in this country, and in Scotland. $\mathrm{He}$ showed me a large bundle of prescriptions he had tried, mainly of digitalis, which bad at times given him temporary relief. Nitrite of amyl he had repeatedly tried but with no benefit. Of late his angina had been unrelieved by digitalis and he was obliged to give up work, hiss attacks getting more frequent; he had bad four in the last fortnight. ordered him six grains of iodide of potassium with onesixteenth of a grain of bichloride of mercury three times daily. He had no attack of angina after this until Sept. 15th or thirty-four days. In this attack the pain was in the chest and down the left arm, but not far down; the attack was slight-in fact, " not worth speaking of"; the paipitation, he said, was much better; he had not been in the same flurried and faint condition as before; and the pulse was 76 per minute, full and soft. The apex of the heart was now one inch below the nipple and one inch inside its line. The impulse was feeble and the jarring tremor over the right ventricle much less; over the left ventricle was heard a weak rather prolonged first sound and a clear second sound with a good interval between them. Over the right ventricle the first sound was louder than before and without brait and there was re-duplication of the second sound. The first sound was hardly audible at the right base. The heart sounds were not hurried as before and the carotids did not throb so demonstratively. He continued to take the medicine till Sept. 9th and greatly improved. On Sept. 17th, on eight days after he left it off, be "came over very bad, being frightened to draw breath," and the pain went down the arm. His pulse was 96 and there was a soft post-systolic bruit. His medicine was resumed kat of increased strength; he again greatly improved. On Oct. 13th the apex was one inch inside bis nipple, there was no bruit, and his beart appeared healtby, except that the first sound was weak; the pulse was 72 , and he could get about well and take exercise freely. On Feb. 18th, 1888, I saw him again, when he was quite well. I have not heard of him since.

CASE B.-I might add another case in which a policeman suffered so severely from angina that he fell down while on duty. There was no bruit or ascertainable evidence of heart disease; his anginal attacks were of intense severity and occurred once or twice while he was at the hospital, on one occasion so severe that I had to take him indoors. Nothing but hypodermics of morphia relieved him. He had to leave the police force, as I found afterwards meeting him by chance in the street. It then occurred to me to put him on iodide ard mercury and his angina soon became very much less.

CASE C.-In another case a gentleman, who suffered from anginal pain so severe as to prevent any exertion came under my care. He had been treated without effect by several practitioners, and as I also failed to relieve him he saw a wellknown physician in consultation with me, but he did not improve. Digitalis, strychnia, and all treatment failed to relieve him, till one day he mentioned to me that he had had 
syphiiis. Iodide of potassium entirely cured him and he is now in perfect health.

CASE D.-A man, aged thirty-two years, came to the outpatient department at St. Mary's Hospital on Nov. 6th, 1890, complaining of pain in the cardiac region of some months' duration, worst in the early morning. There was a sudden vibiatory cardiac impulse, with a drum-like, very abrupt first sound. His pulse was 72 per minnte. He said directly he want to work he got palpitation and pain in the heart region. He had a sharply-cut syphilitic ulcer on the side of the tongue and had had a chancre some years previously. I ordered him mercury and potassic iodide, and on Nov. 13th the impulse was less vibratory, the pain and palpitation gradually lessened under the treatment, and he came to see me in reply to a letter of mine on March 4th, 1891; he was then able to work well and suffered no pain. The first sound was duplicated and the pulse 84 per minute.

CAis F.-A man, aged sixty-one years, came to me at St. Mary's Hospital as an out-patient on Nov. 19th, 1894, complaining of giddiness for three weeks, of sleeplessness, headache for fourteen days (very severe at night), and palpitation. The pulse was 138 , small and running. The heart's apex was just inside the nipple line in the fifth space; there was a very rapid succession of first and second sounds and now and then a beat was dropped; the arteries were degenerate. The patient was very weak and anæmic and depressed. There was no albumin in the urine, the specific gravity of which was 1010 . I ascertained he had had syphilis many years before and he had, indeed, some scarring of an eruption on the back. He took iodide of potassium and bichloride of mercury, and on Nov. 26th the giddiness had become less and he slept better. The headache also was less, His pulse was 160 , very short, and with a slight tapping impulse. The heart sounds were regular. He felt much better and wished to resume work. bui I advised against this. By Dec. 10 th his pulse was 128 and tense; his first heart sound was loud and clear; he felt much better and went to work; and on the 3lst the pulse was 104. He looked a different man; he ate and slept well althongh there was occasional giddiness when he looked upwards and thew suddenly downwaris.

Diffuse syphilitic fibrosis of the heart.-Cases of general fibroid infiltration of the heart may be divided into two classes - those in which the weakened muscular tissue yields to the intra-cardiac pressure and dilatation results, and cases in which the heart wall becomes toughened, stiffened, and thinned, with much loss of power, but without dilatation.

Suphilitic fibrosis lexding to dilatation of the heart.When the Lefi Vertricle becomes thus dilated the evidences are the same as those of dilatation from other conditionsvir. subjective sensations about the cardiac region, even angin? pectoris, ciddiness, faintness, or actual syncopal attacks, with alterations in the force or frequency of the pulse, together with the physical signs of dilatation of the ventricle; the sympterns often are more marked than might be expected from the ainount of dilatation present, probably becuuse the fibroid change resists the dilatation to some extent, though itself greatly enfeebling the heart power in these cases death may occur quite suddenly or only after dilatation of the right ventricle, back-working, and all the symptoms of tricuspid regurgitation have been produced; in some cases these right heart symptoms are due to independent involvement of the right ventricle by the fibroid changes. The table contains cases illustrating the effocts of dilatation of the left ventricle from syphilitic changes. In Case 3 death occurred after some months of well-marked symptows of heart failure, and the left ventricle was found post mortem to be extensively dilated and hypertropbied, and in Case 12. where a woman dropped suddenly dead in the street, the left ventricle was found dilated and hypertrophied. When the Right Ventricle becomes dilated as a result of fibroid change the cases in the table show that suffocative attacks of dyspoœa, ascites, albuminuria with the physisal signs and other evidences of tricuspid regurgitation cccur, and death eventually takes place, but sulden death in the midst of apparent health does not result from fioroid disease of the right side of the heart. It must be, of course, remembered that where the left ventri sle is afected by fibroid disease the right heart dilatation may be only a secondary result of this. Case 4 in the table illustrates the symptoms produced and the fatal results of syphilitic disease of the right ventricle with tricuspid egurgitation. The following cases are examples of dilatation of the heart, probably syphilitic, which improved under treatment.

CASE F.-Dilatation of the left ventricle and syncopal attacks.-A man, aged thirty years, was seen with Dr. S. de Butts on Oct. 12th, 1892; he was married and had three healthy children. He suffered in 1883 from a chancre and secondary syphilis. In 1891 he began to experience a dull pain in the lower sternal region with a feeling of constriction of the chest and palpitation ; and one evening he had semi-syncopal attacks and had to lie down. He had to remain at home a fortnight. A month or six weeks before I saw him in October, 1892 , after feeling much the same sensations as before, he had another semi-syncopal attack and was very breathless; he was just able to get into a cab and go home. No albumin was found in the urine either then or during the previous attack of illness. When I saw him the pulse was 84 per minute and the heart's apex in the sixth space, one inch outside the nipple line. The beat and first sound of the heart were very weak ; the aortic sound was clear; the first sound was occasionally duplicated; there was no bruit; the beart was certainly dilated, and as he had not benefited by digitalis or strychnia, was in good general health. but had suffered from syphilis, the diagnosis of possible syphilitic change in the left ventricle was arrived at and he was ordered mercury and iodide of potassium; the signs of dilation rapidly closed up. Dr. de Butts tells me he has been well since then, except that once or twice the symptoms have recurred. Each time he has resorted to the same treatment and soon got well. About August, 1896, he had a sort of anginal attack, which he treated in the same way.

The following case is recorded by Lancereaux in his "Treatise on Syphilis," p. 393 :-

CASE G.-A woman, aged thirty-seven years, entered the Hôtel Dieu for exostoses on the tibir. She had contracted syphilis six years before and it was evident it was to this disease that the exostoses were attributable; but she was, moreover, pale, emaciated, and her liver projected three fingers' breadth below the ribs. She had shortness of breatb, a feeling of oppression in the precordial region, and violent palpitations. Percussion showed that the heart was enlarged and auscultation revealed a slight blowing sound; the movements of the organ were irregular and the pulse feeble and compressible. Not seeing anything to explain the drrangements of the heart and liver he suspected that the lesions of those organs might be connected with syphilis and this opinion was afterwards confirmed by the effect of treatment with iodide of potassium.

CASE H. - In a second case recorded by the same author the patient, a young man, admitted to the Hôtel Dieu suffered from greatly enlarged liver, cedema of the extremities, and irregular movements of the heart, which did not appear enlarged, and without any abnornal sounds. For several months he had suffered from oppression on the chest. Despite the absence of any avowed antecedent syphilis he was put on iodide of potassium, and the oppression disappeared, the heart regained its regularity, and the liver diminished in size so as no longer to project by more than one or two fingers' breadths below the margin of the ribs. The cachexia was at the same time replaced by a certain degree of stoutness.

CASE I. - A labourer, aged forty three years. was admitted to St. Mary's Hospital on June 3rd, 1896. He had been a soldier for twelve years. He had had good health except for venereal disease, for which he was in hospital. About six weeks previously he first had attacks of shortness of breath, especially at night, obliging him to be propped up in bed or to get up and walk about the room. $\mathrm{He}$ has been unable to walk more than fifty yards at a time and had to give up work. Not improving under treatment as an out-patient he came into the hospital on June 3rd; his pulse was 90 , irregular, both in force and frequency ; the apex beat was in the sixth space half an inch external to the middle line, feeble, flattering, and diffuse, and there was slight epigastric pulsation. There was a blowing, short, systolic murmur. The other heart sounds were clear, the liver was much enlarged the dyspnoea was considerable, though nothing abnormal was found in the lungs. With complete rest in bed and digitalis and strychnia he improved to some extent, the liver lessenıng in size, and he felt quite well in himself, but he was unable to walk even about the ward and the heart was most irregular in action. On July $2 \mathrm{nd}$, after he had been op, the heart was beating faster than it had been. Epigastric palsation was very marked; the cardiac dulness was increased and frequently the beats did not reach the wrist. On July 7th 
I found that at the apex there was a bruit with some beats, but not with all, that the action of the heart was extremely irregular and the breathing very embarrassed by the slightest exertion, and it was more irregular than ever. As no treatment had given much benefit he was ordered mercury and potassic iodide; he began to improve, and by July 21 st said he was better than he had been for years. The apex was in the vertical nipple line; the heart above was more regular, though still at times there was an irregularity and systolic murmur, and the pulse was more forcible, but by no means regular The heart condition was a long way off being normal, but he was so well that he would return to work. and he was able to do the heavy work of a crane driver till about Sept. 17th, when he began again to have dyspncea, but managed his work without much difficulty. On Sept. 23rd he came to see me; his pulse was 108, very irregular in force and frequency; the first sound had a systolic murmur with it at some beats, but not at others, and the action was irregular. I persuaded him to come in again and by Oct. 4th he was very much better, and bis pulse was 92 under specific treatment and rest. This case was one of very marked cardiac degeneration of some sort giving dilatation and much dyspncea; both sides of the heart were certainly dilated. He got much better in a very short time by specific treatment after resisting other methods.

Diffuse fibroid heart-change without dilatation (a) in the left ventricle.-In this condition, exemplified by some of the fatal cases in the table, a gradual and progressive loss of power ensues; where the change is limited in extent little is to be found except that the heart's impulse and first sound are weak and there may be some symptoms of cardiac weakness. In adranced cases the action of the heart may get extraordinarily weak, the apex beat becoming imperceptible and the first sound almost or quite inaudible; the pulse is very feeble, irregular, or very rapid or very slow, or alternating between these two conditions; there is a tendency to giddiness, faintness, and syncopal attacks may occur. At times the cardiac symptoms may become orershadowed by those of extreme debility, with inability for any exertion and great loss of energy, sometimes so marked that the patients have to keep their beds; there may be cedema of the feet and there is marked anæmia. Such cases are gradual in development and may go on in this condition for a long time with exacerbations and improvements: they are often put down as fatty heart or as "weak heart," and weak heart they undoubtedly are, but the weakness is due to organic change. These cases unless relieved by treatment die suddenly or from gradual asthenia. Several cases in the table exemplify the fatal results of syphilitic infiltration of the left ventricle without dilatation. Thus in Case 9 in the table "a correct diagnosis was made of a specific cardiac lesion from the peculiar feeble contraction of the heart and the empty arteries, the left ventricle and septum being found post mortem to be the seat of extensive fibroid infiltration creaking on section"; and in Case 19 in the table a man aged forty-five years died suddenly from extensive syphilitic infiltration of the wall of the left ventricle completely destroying the muscular tissue. Case 20 in the table is very similar. When the right ventricle becomes fibrotic without becoming dilated the main symptom would appear to be dyspncea, as in cases where there is dilatation. Probably such disease of the right ventricle alone is not likely to be fatal, but if it involves the septum it may be, as in Case 7 where a man after walking across some fields fell dead in a public house, the necropsy showing extensive fibroid change limited to the right ventricle, septum, and musculi pectinati.

The following appears to be an example of fibroid disease of the heart without dilatation resulting from syphilis.

CASE J.-A man, aged thirty years, came to me at St. Mary's Hospital on Oct. $30 t h, 1885$, complaining of precordial pain of five or six months' duration, with palpitation, dyspnoa (especially after exertion), giddiness, faintness, languor, and aching pains in the knees and shoulders, worst at night; he also had sweats at night. The pulse was 84, of rather high tension; the arteries of the neck throbbed. The apex of the heart was in the fifth interspace, a little inside the nipple line. There was a re-duplicated first sound, which was very weak over the left ventricle, but no bruit. He was treated with digitalis, with strychnia, with both combined, with tonics, and with ergot successively. He got worse rather than better ; he could not sleep; his pulse varied from 104 to 112 per minute and was always feeble; he got very haggard-looking and could not resume work though he refused to become an in-patient. In Jannary, 1886, I discovered that a child under my care at Paddington.green Children's Hospital for congenital syphilis was his child. On inquiry from him I found that ten years before be had had a chancre. On Jan. 14th I ordered him iodide of potassium and mercury. On the 21st he was "better than he had veen all along." The pulse was 100. On Feb. 2nd his Leart sounds were much louder and clearer and his symptoms gone. He soon went again to his employment and $T$ wrote to him on Dec. 16th, 1886, and heard from him that he was cuite well and living in the country.

The two following fatal cases also exerpplify the results of fibroid change in the heart without dilatation. mey bave rot been included in the table, for their nature not being suspected during life enquiry was not made into svoullitic antecedents. From evidence afterwards obtained $I$ bolieve they were syphilitic. Fagge has shown that fibroid disease frow syphilis cannot be distinguished from fibroid disease from other causes even on the post-mortem table, $\epsilon$ xcept wharc there are actual gummata iu addition. Wbe symptoms, iben of syphilitic fibrosis are in all probability identical with thes of non-syphilitic fibrosis of the heart, and eren if these cases are not of demonstratively proved syphilitic cansation they were certainly cases of fibroid disonse such as syrhilis produces and may be taken as exemplifying the symptosis syphilitic fibrosis may produce.

CASE K.-This patient, a marriea womas, aged forty eight years, soon after a confinement in 1877 commenced to feel weakness and languor. She came to me in $1884 \mathrm{n}$ an out-patient and on Sept. 3rd, 1884, I took her into tho hospital. She complained of pains in the head and attroks of giddiness, during which she had often fallen but withon Ioss of consciousness. She was very sbort of breath on siog up steps and her voice was very weak. There wa uo dyspncea when lying down. There was no albuminuria ard no impulse of the heart was perceptible and no "first sound" was audible. The pulse was 64 per minue, very weak. remained in the hospital till Oct. 8th, during which time the first sound of the heart could at times be faintiy heard. She preferred to lie in bed always and showed a peculiar larguor and want of energy. She occasionally fainted. She was very anæmic and as it was thought she mignt be suffering from pernicious anremia the red corpuscles were counted and were found to be about 70 per cent of the normal. She wis given arsenic, iron, ergot, digitalis, \&o., with little rasult except that her gums got rather spongy when the areenio was pushed. Dr. Broadbent kindly saw her with me and agreed that she was suffering from extreme cardyo debility. There was never any rise of temperature nro the pulse varied from 60 to 76 a minute. At times she improved and during such temporary improvement went home on Oct. 8th. I went to see her at hons at times after this, being interested in the case, and was informed, in October. 1885, that she had died sudaenty in Kensington Infirmary. I made a post-mortem examinasion when all the organs were found to be healthy except that too heart was tough and fibrous and the musculi papillares quite rigid and the edges of the mitral cusps were soldered together.

UASE L. - $\Lambda$ woman, aged thirty-eight years, who had been married twenty years, came to me at St. Mary's Hospital as an out.patient in February, 1890. She said that she had sor a long time suffered from palpitation and faintness. She bad had ten children, of whom five luad died in infarcy. Since the last confinement, in September, 1889 , the palpita tion had been worse. There was epigastric pain and once she had fallen to the ground in a faint. Her heart action was very feeble and rapid, and as treatment by digitalis and tonics failed to relieve her I sent ber into the hoscital on April 15th, 1890. She continued to sufier from palpitid. tion, occasional vomiting, and extreme languor; the pulse was extremely feeble, beating often 160 a minute, at the times too fast to be counted; at times the pulse would $k$ uddenly become very slow, sinking to 40 a minute, but the heart was then found to be beating 80 a minute, the apex beat was very feeble, but was inside the nipple line, and the heart did not appear to be enlarged; there were no murmurs Strophanthus appeared at times to relieve her. On June 17th. being a little better, she went to a convale cent home. She returned as an out-patient on July Ath as bad as ever, with swelled feet, slight oedema of the face, marked sallowness of complexion, and a pulse rate of 180 $I$ sent her in-doors again. She then kept her bed, but 
frequently fainted when she sat up and often became cold and clammy. On one attack on July 18th she was with difficulty revived by stimulants and ether; her face at times flushed up, but she was usually pale; the left leg at times swelled a little; the first leart sound was always very feeble and the second sound often dropped; the action was frequently irregular; usually there was a series of rapid beats with iatermission; no diagnosis was made except of cardiac weakness, and digitalis, strophanthus, arsenic, convallaria majalis, and irou were tried without avail. When the hospital was closed for cleaning she was admitted into the Middlesex Hospital, where her husband was a patient with tabes dorsalis, While there a slight systolic murmur was heard and it ras noted that digitalis did no good. After being eleven days in the hospital she died in September quite suddenly and unexpectedly when she was thought to be convalescing At the necropsy there was found a general fibrous myocardial change and oedema of the lungs. For this account of ber stay in the Middlesex Hospital I am indebted to the kindness of Dr. Wynter, assistant physician a's that hospital.

These two cases illustrate very well the very gradual failure of heart power produced by fibroid heart disease and the languor and weakness to which such patients are reduced, together with tha complete failure of cardiac tonics to give ralief. During life others besides myself saw the patients and agreed that the one thing that was certain was that there was a conditiou of extreme cardiac weakness unlike that of fatty disease, and of which the causation was not explainable.

Cases in $n 7 i$ ich there is hypertrophy of the heart.-It will be seen that in several of the fatal cases in the table there was found pust mortem considerable hypertropby of one of the ventricles. In such cases the increased bulk of the heart is produced by abroid tissue and not by increase of muscular tibre. The diagnosis of such cases rests on the evidences of hypertrophy of the heart without evident cause ; where there is no valve disease or albuminuria, and nothing to indicate that the hypertrophy has been set up by great muscular exertion, and where pericardial adhesions are not present, it should be remembered that hypertrophy may result from interstitial fibroses, and this becomes especially probable where the increased bulk of the heart as estimated by the physical signs is not accompanied by evidences of proportionate increase of power. Where the heart-beat is very owerful and the arteries not well filled there is a presumption that the hypertrophy is not a true hypertrophy, and it should be remembered syphilis is a cause of such spcrious bypertrophy of the beart. Such cases may terminate fatally quite suddenly $s, 8$ in Case 5 and Case 16 in the table there was enormous luppertrophy of the left ventricle and an aneurysm near the apex.

CASE M.-A woman, aged fifty-three years, came as an out-patient to St. Mary's Hospital on Oct. 18th, 1886, complajning of palpitation waking her at night, headache, and faint attacks. The pulse was 100 and irregular. The first and second sourids were re-duplicated; the first sound was a little rough, but there was no actual bruit; there was a very forcible heaving impulse over a large area, and the apex itself appeared to be just outside the nipple line. The second sound was loud and clanging. She improved somewhat for a time with digitalis and iron, but at times fainted, and the palpitation continued. In December I noticed a red scar on the chin. and on inquiry found that it resulted from a specific ulceration for which she had attended my colleague, Mr. Ir Morris. Her heart symptoms were very soon relieved by mercurial and iodide treatment. Since then they have recurred from time to time and she has frequently come back to me at the hospital and always been relieved by anti-syphilitic treatment. The apex of the heart is in the same position atd the impulse forcible, but the symptoms are relieved.

Cardiac aneur;sms from syphilitic disease. - The cases in the table showed thiat in many of the fatal cases aneurysm of the heart-wall had resulted from the syphilitic changes; in some cases death hal resulted from rupture of such aneurysms, in others death bad occurred from other syphilitic heart lesions. Probaliy most cardiac aneurysms, when not traumatic. result from syphilitic disease of the heart wall and early recognition of the presence and nature of fibroid cardiac lesions would prevent their formation. In this paper I shall not $d w e l l$ at more length on these cardiac aneurysms, but the following case, the notes of which have been kindly given me by a military surgeon, is of interest as showing how angina pectoris may be almost the sole evidence of an aneurysm of the heart wall, in this resembling a cardiac gumma (of which it is the later stage) and aneurysm of the aorta at the sinus of Valsalva.

CASE N.-A man, aged twenty-five years, a soldier of seven years' service, was under treatment in 1889 and 1890 for syphilis in a military hospital for 185 days ; after that his health was good. He was admitted on Nov. 4th, 1893, into the Station Hospital, Gosport, for indefinite pains in the chest, principally on the right side, whence they extended down the arm. The temperature was normal ; there were no physical signs of disease of the respiratory or circulatory organs. On Nov. 5th a severe paroxysm of pain occurred; again on the 6 th at 3.30 A.M., and at $8.10 \mathrm{~A}$ M., with vomiting; the extremities became cold, the face pallid, and the pulse imperceptible, and he died in ten minutes. The necropsy showed a small opening concealed by one of the aortic cusps leading into an unruptured aneurysmal sac at the base of the aorta; the wall of the aneurysm was composed of the heart muscle forming a cardiac aneurysm.

\section{DIAGNOSIS}

Of very small gummata in the heart wall, which give no symptoms, the diagnosis is not possible, but they are not of serious importance. Larger gummata in the left ventricle gave rise to physical signs and symptoms. The physical sign are an enfeeblement of the apex beat and the first cardiac sound, or in some cases where the gumma is near the apex evidences of interference with the heart's action, such as abrupt, rapid, apex beat and noisy, short first sound; often the cardiac action is extremely irregular or altered in rhythm. The symptoms are one or more of the following: subjective sensations about the heart, palpitation, giddiness, attacks of faintness or actual syncope, epileptiform attacks, a very rapid or irregular (or perhaps a very slow) pulse, and, above all, anginal seizures. It must be admitted that no one of these physical signs or symptoms-angina excepted-necessarily implies the existence of cardiac disease. Syphilis has been called the "great imitator," and here it imitates gastric or reflex or functional unimportant ailments; and the difficulty in these cases is not so much to decide what form of cardiac disease is present as to decide if there is any heart disease at all. It is not al ways possible to overcome this difficulty, though it usually is, but I wish to insist on this important fact, that evidences which we might sometimes st t aside as too slight to denote important cardiac disease must not be so set aside in syphilitic persons. Certainly angina pectoris, with the slight physical signs enumerated above, must be taken as affording strong probability of a gumma in the heart in syphilitic persons, even without another symptom. Of the other symptoms named no one indiridually is pathogno. monic of organic heart disease, but if there be more than one of them-e.g., syncope and palpitation-with the slight characteristic physical signs, there is a similar probability in syphilitic persons. Gumma of the right heart may be suspected from dyspncea unaccounted for by left heart disease or lung disease or dilatation of the heart when with it there is the slightest evidence of right heart difficulty in syphilitic persons. One factor influencing the diagnosis in all cases will be the evidences of previous syphilitic infection and the results of specific as compared with those of non-specific treatment; such evidence is always regarded as important in disease of other parts of the body, and we are not more or less dependent upon it in the diagnosis of cardiac syphilis than we are in the diagnosis of visceral syphilis in general.

Diagnosis of dilatation of the heart from syphilitic disease of the heart wall.-Inquiry into the previous history, the habits, and the general condition of the patient is required in determining whether any dilatation of the heart from which he is suffering is attributable to syphilitic disease of the heart wall. If the left ventricle is found to be dilated without valvular disease, nephritis, or other canses, which produce increased strain upon the heart fibre, it may be concluded that the dilatation is due to parietal weakness. Of the conditions producing such weakness fatty degeneration may be for the most part excluded, for it rarely gives rise to dilatation but if it is suspected the age of the patient and the usual data which guide us in the recognition of fatty disease must be appealed to. Apart from fatty disease debility of heart fibre can only be due to myocarditis in some form; and if there be no history of acute fever or illness, and ther is not present any cachectic state to weaken the heart muscle, the myccardial change is in all probability a fibrous one; this becomes still more probable if no improvement results from the usual cardiac tonics; and if 
the patient has a history or traces of syphilis, and specific treatment succeeds where digitalis, \&c., has failed, there remains very little doubt that the dilatation of the ventricle is the result of syphilitic fibrosis. In certain cases of syphilis the patient becomes cachectic, anæmic, and feeble, with or without pyrexia, and some dilatation of the heart may occur as a result of the general condition. Without any fibroid heart lesion the dilatation and general condition improve together in these cases under anti-syphilitic treatment, but they are readily distinguishable from cases in which, the general health being good, there is dilatation from syphilitic disease of the heart wall. Dilatation of the right ventricle from fibroid heart disease is, perhaps, more difficult of detection than of left heart dilatation. This, however, it has in common with dilatation of the right heart from other causes. But that dyspncea is produced by dilatation of the right heart from fibroid disease and that it is a very constant symptom in such cases is proved by the history and post-mortem appearances in many of the cases in the table; and in syphilitic persons persistent or paroxysmal attacks of dyspnoea without obvious cause, and even with but slight signs of right heart enlargement, should be looked on as possibly resulting from fibroid change.

Diagnosis of diffuse fibroid syphilitic disease of the heartwall without dilatation.-When the fibroid change is of limited extent, though not forming a gummatous nodule, the only symptoms will be those such as are producible by gummata; in such cases the probability of the heart weakness being aue to syphilitic fibroid change must be adjudged upon by taking into consideration the age of the patient, the results of inquiry into possible syphilitic infection, and the effects of the ordinary cardiac tonics as compared with those of specific treatment. A due con sideration of these will in many cases enable the cases of heart weakness from syphilis to be distinguished from those resulting from other causes.

When the fibroid change on the left ventricle is widespread, involving, perhaps, the musculi papillares as well as the ventricle wall, the cardiac debility gradually increases till it becomes extreme and the diagnosis is not difficult indeed, it is much more readily made than in those case where dilatation is present, for while many causes produce cardiac weakness with dilatation the causes of great cardiac weakness without it are few - in fact, only fatty disease; but this can only produce such extreme heart weakness as widespread fibrosis causes when present in an extreme degree, and then, as Walshe ${ }^{10}$ points out, "its clinical evidences are more or less precise and positive." In addition, the age of the patient and the previous history will often enable us to distinguish between the two conditions. The course, too, of fibroid disease is very different from that of fatty degeneration, for when the latter has once reached such a point as to produce syncopal attacks, and irregular or almost imperceptible pulse, death ensues, whereas in fibroid disease patients may suffer from cardiac weakness sufficient to prevent their moving about and to suffer from a languor and apathy they cannot overcome and to keep them almost to confinement in bed and yet go on for months in much the same state. The distinction between diffuse fibrosis and fatty degeneration of the heart is not usually difficult. (This was evidenced in the two cases $K$ and $L$, in both of whom it was agreed by those who saw them that there was extreme cardiac debility, but that it was not due to fatty degeneration.) These cases of general fibroid disease of the left ventricle without dilatation may be diagnosed when in persons mostly in mid-life sometimes later on there occur manifestations of a very chronic, gradually increasing cardiac weakness, with an extremely feeble pulse, sometimes very rapid and sometimes suddenly becoming slow, with tendency to syncope and an extreme general feeling of weakness, and with increasing languor and apathy. These cases do not improve under cardiac tonics, though they may temporarily give promise of improvement, especially under strophanthus.

Treatment of syphilitic disease of the heart nall.-This is the same as of syphilis of other internal organs.

CONCLUSION.

1. Syphilis may produce gummata or general fibroid change. 2. Gummata in the left ventricle, except of very small size, are dangerous to life, and when near the apex of the left ventricle may cause sudden death. 3. Gummata in the left ventricle may be suspected if in an individual with syphilitic antecedents there occur signs of derangement of the action of the left ventricle with symptoms of defective or embarrassed action, especially angina pectoris, tachycardia, syncopal or epileptiform attacks, or in the right ventricle when dyspnœa otherwise un accountable occurs. 4. Extreme feebleness of the heart without dilatation gradually increasing in young or middleaged persons who have had syphilis suggests syphilitic disease of the left side of the heart, and long-standing dypsncea may point to similar disease on the right side of the heart. 5. Dilatation of either side of the heart in syphilitic persons may result from syphilitic fibrosis. 6. Hypertrophy of the heart without ascertainable cause and without corresponding increase in strength of heart suggests syphilis. 7. Aneurysm of the heart wall may result from syphilitic local lesions and may be fatal with or without rupturing. 8. It is probable that gummata and fibroid disease in early stages may be relieved or cured by the usual specific treatment, and there is every reason to believe that syphilitic lesions of the heart wall are not less amenable to treatment in their early stages than syphilitic lesions elsewhere, though no cure can be expected where advanced tissue changes are already produced. In what I have written I have devoted attention only to syphilitic disease of the heart wall apart from valve disease. It is certain that the small number of cases I have given in the table (and I might have added many more) must repre sent a much larger number of unrecorded fatal cases-cases in which no necropsy was performed or the fibroid condition was not recognised or reported, and a very greatly larger number of cases of persons who have suffered from syphilitic heart lesions without their producing death. It is, therefore, certain that syphilitic heart disease is more common than is generally recognised. And its importance is the greater because it afrects persons at an earlier age that the usual degenerative heart conditions and may insidiously advance till it causes sudden death in persons in the prime of life and of apparent health.

There can be little doubt that syphilitic heart affections must affect the administration of anæsthetics, more especially as a life-long disease like syphilis is apt to produce local conditions that require operative interference not infrequently. Certainly cases are bronght in of death under an anzsthetic from fatty disease of the heart in which the chief evidence of that condition is that the patient died under anæsthetic, and at the moment I write a case ${ }^{11}$ is recorded of death under the administration of the A.C.E. mixture in which "the right ventricle was found dilated with fatty infiltration of its walls; the left ventricle was also dilated and there was some fibrosis of its walls." $\mathrm{Dr}$. Kirk ${ }^{12}$ found that chloroform, if we may judge from a few cases, is liable to give dangerous results in syphilitic subjects.

Upper Berkeley-street, W.

\section{THE REMOVAL OF SUPPURATING PELVIC TUMOURS : ILLUSTRATED BY TWO CASES.}

BY ALBAN DORAN, F.R.C.S. KNG., SURGEOY TO THE SAMARITAN TREE HOSPITAL.

THE two cases which are related in this communication offer certain instructive features in common. In both the structures which were removed contained pus, and in both the tissues "of the pedicle were unhealthy, not from infiltration of any new growth, but from inflammatory changes. Both patients were restored to health, but the details of treatment involve matter for comment. The chief subjects worth consideration are the management of unhealthy pedicles, washing out, and drainage.

CASt 1.-On March 8th, 1894, my friend Dr. Ilott of Bromley consulted me about a girl aged sixteen years who had been under his care for six weeks. She was thin, but had been fairly healthy till the present illness. When Dr. Ilott first saw her she showed symptoms of peritonitis an

Il Brit. Med. Jour., Feh. 3rd, 186

12 Ibid., Dec. 12th, 1896, p..1706. D 2 